\title{
First report of Iris yellow spot virus in Costa Rica
}

\author{
Mauricio Montero-Astúa ${ }^{1,2}$ (ID $\cdot$ Natasha Dejuk-Protti $^{1,2} \cdot$ Elena Vásquez $^{1} \cdot$ Laura Garita $^{1}$ • \\ Lisela Moreira $^{1,2}$
}

Received: 17 February 2017 / Accepted: 28 March 2017 / Published online: 11 April 2017

(C) Australasian Plant Pathology Society Inc. 2017

\begin{abstract}
Iris yellow spot virus (IYSV), an emerging disease of onion crops, was identified by transmission electron microscopy, enzyme linked immunosorbent assay, and reverse transcription polymerase chain reaction in Costa Rica. Onion plants had straw-colored, elongated lesions and tip dieback. Costa Rican IYSV nucleocapsid partial sequences (15 isolates) grouped with isolates from North and Central America and from New Zealand.
\end{abstract}

Keywords Iris yellow spot virus · IYSV · DAS-ELISA . TEM $\cdot$ RT-PCR $\cdot$ Virus detection

Iris yellow spot virus (IYSV) is an economically important plant virus in the genus Tospovirus, infecting onion and garlic crops and bulb ornamental plants worldwide. IYSV is transmitted by two species of thrips (Thysanoptera): Thrips tabaci (Kritzman et al. 2001) and Frankliniella fusca (Srinivasan et al. 2012). Since the first report of the virus in Brazil, it has been reported in numerous countries in Africa, North and South America, Asia, Europe, and Oceania, and since 2003 this tospovirus is associated to disease epidemics in the USA and other countries (reviewed in Pappu et al. 2009).

Herein, we report the detection of IYSV in Costa Rica and we noticed inconsistency in detection results among ELISA

Mauricio Montero-Astúa

mauricio.monteroastua@ucr.ac.cr

1 Centro de Investigación en Biología Celular y Molecular (CIBCM), Universidad de Costa Rica, San José 11501-2060, Costa Rica

2 Escuela de Agronomía, Universidad de Costa Rica, San José 11501-2060, Costa Rica and different primer pairs for RT-PCR. During 2013 and 2014, onion crops in two growing areas on Costa Rica's Central Valley (Cartago and San José provinces) were visited due to the presence of straw-colored, elongated lesions; tip dieback and extensive drying of leafs (Fig. 1a-d). These symptoms were similar to those described for IYSV infection in Georgia (USA) and Peru (Nischwitz et al. 2007); however, diamond-shaped lesions with a green center, a diagnosis-value symptom (Pappu et al. 2008), were observed seldom. Additionally, all the visited fields had high numbers of onion thrips (T. tabaci) further suggesting IYSV may be the causal agent of the observed symptomatology. Therefore, 18 leaf symptomatic samples (individual plants) were collected, ten and eight from Cartago and San José provinces, respectively. Samples were evaluated by DAS-ELISA (per duplicate wells) with specific antibodies against IYSV (Agdia, Elkhart, USA), according to the manufacturer's instructions and using positive and negative controls from the same supplier. Positive results were those with average absorbance values greater than twice the absorbance values for negative controls $(n=4$ wells/plate). Ten out of 18 samples (56\%) tested positive by ELISA for IYSV infection (Table 1).

Two samples, $1 \mathrm{~A}$ and $2 \mathrm{~B}$, and a compound sample consisting of tissue sections from samples collected from the same locality (4D to 10D) were evaluated by transmission electron microscopy (TEM). Small leaf segments $(1 \times 2 \mathrm{~mm})$ were harvested around necrotic lesions on symptomatic onion leaves and fixed in Karnovsky solution (Karnovsky 1965) in $0.05 \mathrm{M}$ cacodylate buffer $\mathrm{pH} 7$ at 6$8{ }^{\circ} \mathrm{C}$. Fixed tissue was processed and embedded in Spurr's epoxy resin (Spurr 1969) as described by Montero-Astúa 
Fig. 1 Symptoms associated to Iris yellow spot virus infection on yellow (b, d) and red onion varieties $(\mathbf{a}, \mathbf{c})$ in Costa Rica. Plants have multiple lesions and necrotic leaf tips (a); as the infection progresses lesions coalesce and complete areas of the leaf blade die (b). The common symptom observed is elongated dry areas in the leaf blade (c, d). Vesicles (arrows) containing tospovirus-like particles observed by transmission electron microscopy of symptomatic onion leaf tissue (e). Images correspond to samples $16 \mathrm{G} \mathrm{(a,} \mathrm{c);} \mathrm{13F} \mathrm{(b);} \mathrm{4D} \mathrm{(d);} \mathrm{and}$ 2B (e)
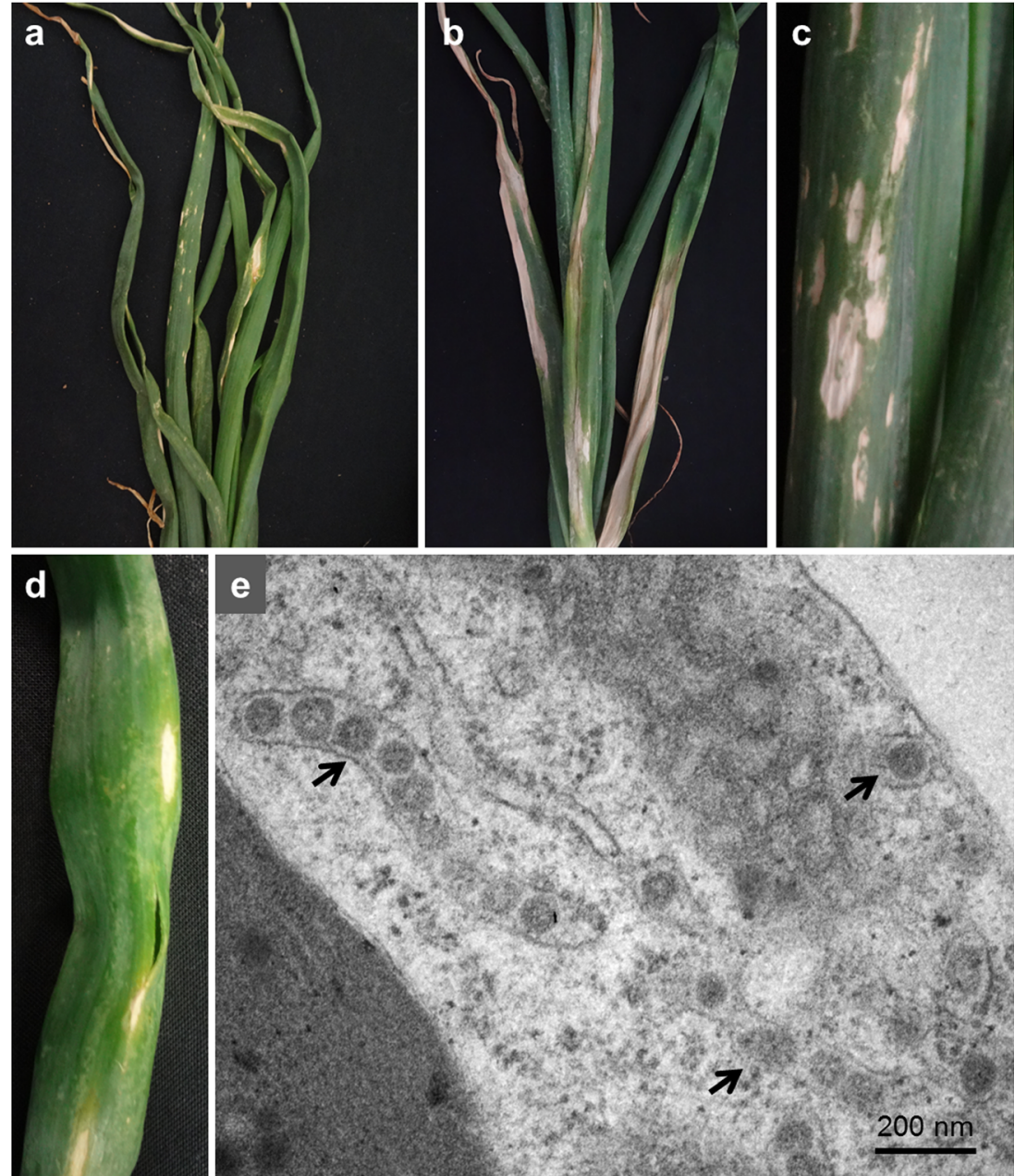

et al. (2008). Thin sections were obtained with a diamond knife and an ultramicrotome (Power Tome PC, RMC) and stained for 5 min with $2 \%$ uranyl acetate aqueous and for 2 min with Sato's modified lead stain method (Hanaichi et al. 1986). Grids were observed using a Hitachi H-7100 electron microscope (Tokyo, Japan) at $100 \mathrm{kV}$. We observed numerous spheroidal membranous particles, with an average diameter of $79.81 \pm 10.28 \mathrm{~nm}(n=795$ virions, range 50.00 to $114.80 \mathrm{~nm}$, measured using ImageJ software, Schneider et al. 2012). The particles were found within membranebound vesicles in the cytoplasm as double enveloped virions (DEV) or as groups of virions (Fig. 1e). The shape and size of the particles found on the samples resembled those typical for tospoviruses (Whitfield et al. 2005).

To confirm the presence of IYSV, samples were tested by RT-PCR with specific primers. Total RNA was extracted using RNeasy Plant Mini Kit (Qiagen, Hilden, Germany) and cDNA was synthesized with random hexamers using Maxima $\mathrm{H}$ Minus First strand cDNA Synthesis Kit (Thermo Scientific, Lithuania) following the manufacturer's instructions. PCR reactions were performed in $25 \mu \mathrm{L}$, containing $2 \mu \mathrm{L}$ of cDNA, $12.5 \mu \mathrm{L}$ of $2 \mathrm{X}$ DreamTaq PCR Master Mix (Thermo Scientific, Lithuania), and $200 \mathrm{nM}$ each primer. Initially, samples were tested with primers IYSV-465c and IYSV-239f (Pappu et al. 2008) with the following thermal profile: $95{ }^{\circ} \mathrm{C} \times 3 \mathrm{~min} ; 35 \times\left(94{ }^{\circ} \mathrm{C} \times 30 \mathrm{~s}\right.$, $\left.60{ }^{\circ} \mathrm{C} \times 30 \mathrm{~s}, 72{ }^{\circ} \mathrm{C} \times 20 \mathrm{~s}\right) ; 72{ }^{\circ} \mathrm{C} \times 5 \mathrm{~min}$. No amplification product was obtained with that primer pair under our experimental conditions. Similarly, Krauthausen and collaborators (2012) reported no amplification for some samples with this primer pair at $60{ }^{\circ} \mathrm{C}$ annealing temperature. Therefore, samples were tested with two additional primer pairs: IYSV-837/Tos-R15 (Uga and Tsuda 2005) and JJ-232f/JJ-692r (Krauthausen et al. 2012); and 14 and 13 samples were positive, respectively. In total, $89 \%(16 / 18)$ of the samples were confirmed to be IYSV-positive with one or 
Table 1 Detection of Iris yellow spot virus in onion leaf samples in Costa Rica

\begin{tabular}{|c|c|c|c|c|c|c|}
\hline \multirow[t]{2}{*}{ Sample ${ }^{\mathrm{a}}$} & \multirow[t]{2}{*}{ GenBank Accession Number } & \multirow[t]{2}{*}{ Province } & \multirow[t]{2}{*}{ ELISA $^{\mathrm{b}}$} & \multicolumn{3}{|l|}{ RT-PCR ${ }^{b, c}$} \\
\hline & & & & $\begin{array}{l}\text { IYSV-465c } \\
\text { /IYSV-239f }\end{array}$ & $\begin{array}{l}\text { IYSV-837 } \\
\text { /Tos-R15 }\end{array}$ & $\begin{array}{l}\mathrm{JJ}-232 \mathrm{f} \\
/ \mathrm{JJ}-692 \mathrm{r}\end{array}$ \\
\hline $1 \mathrm{~A}$ & KY569524 & Cartago & + & - & + & + \\
\hline $2 \mathrm{~B}$ & KY569525 & Cartago & - & - & + & - \\
\hline $3 \mathrm{C}$ & KY569526 & Cartago & - & - & + & + \\
\hline $4 \mathrm{D}$ & Not sequenced & Cartago & - & - & - & + \\
\hline $5 \mathrm{D}$ & No amplification & Cartago & - & - & - & - \\
\hline $6 \mathrm{D}$ & KY569527 & Cartago & + & - & + & + \\
\hline $7 \mathrm{D}$ & KY569528 & Cartago & - & - & + & + \\
\hline $8 \mathrm{D}$ & KY569529 & Cartago & - & - & + & - \\
\hline $9 \mathrm{D}$ & No amplification & Cartago & - & - & - & - \\
\hline $10 \mathrm{D}$ & KY569530 & Cartago & + & - & + & - \\
\hline $11 \mathrm{E}$ & KY569531 & San José & + & - & + & + \\
\hline $12 \mathrm{E}$ & KY569532 & San José & + & - & + & + \\
\hline $13 \mathrm{~F}$ & KY569533 & San José & + & - & + & + \\
\hline $14 \mathrm{~F}$ & KY569534 & San José & + & - & + & + \\
\hline $15 \mathrm{E}$ & KY569535 & San José & - & - & - & + \\
\hline $16 \mathrm{G}$ & KY569536 & San José & + & - & + & + \\
\hline $17 \mathrm{G}$ & KY569537 & San José & + & - & + & + \\
\hline $18 \mathrm{G}$ & KY569538 & San José & + & - & + & + \\
\hline
\end{tabular}

${ }^{\mathrm{a}}$ Letters represent different fields. Samples $1 \mathrm{~A}$ to $15 \mathrm{E}$ correspond to yellow onion varieties; $1 \mathrm{~A}$ to $10 \mathrm{D}$ var. not known, $11 \mathrm{E}, 12 \mathrm{E}$ and $15 \mathrm{E}$ var. Rapsodia; $13 \mathrm{~F}$ and $14 \mathrm{~F}$ var. Aquarius; and $16 \mathrm{G}$ to $18 \mathrm{G}$ are the red onion variety Mata Hari

b “+”" = positive sample for the presence of IYSV, and "-" = negative sample

${ }^{\mathrm{c}}$ Different primer pairs used for IYSV detection by RT-PCR both primer pairs (Table 1). The two samples that failed to amplify by the different PCR reactions were also ELISA negative. Six samples tested positive by RTPCR, although; were ELISA negative. Uncertain diagnosis based on leaf symptoms and discrepancies between ELISA and RT-PCR results were reported previously (Krauthausen et al. 2012). Moreover, the distribution of IYSV throughout an infected plant is uneven (Kritzman et al. 2001; Smith et al. 2006) and thus the pieces of tissue used for ELISA and RT-PCR may contain differential virus titer, even when extracted from the same plant. The low frequency of diamond-shaped lesions (diagnosis-value symptom) may be due to different onion varieties and/or weather conditions (Nischwitz et al. 2006, 2007).

To confirm the RT-PCR results and gain information on the diversity of IYSV in Costa Rica, 14 amplicons obtained using primer pair IYSV-837/Tos-R15 and six amplicons (randomly selected) for primer pair JJ-232f/ JJ-692r were directly sequenced (Macrogen Inc., Korea) using forward and reverse primers, respectively.
Sequences obtained with both primer pairs overlapped; therefore, a final contig per sample (total 15 isolates) was assembled with all the obtained forward and reverse reads. MegaBLAST (National Center for Biotechnology Information, U.S.) first hit for each sequence had 97 to $99 \%$ identity with IYSV sequences from Mexico (KX443602 and KX443603) or New Zealand (EU477515). These results confirmed the detection of IYSV in onion samples from Costa Rica. Moreover, the IYSV partial $\mathrm{N}$ sequences (accession numbers KY569524 to KY569538) were aligned against a selection of IYSV sequences worldwide (Nischwitz et al. 2007; Krauthausen et al. 2012; Iftikhar et al. 2014) with MEGA7 (Kumar et al. 2016) using MUSCLE (Edgar 2004). Phylogeny was inferred in MrBayes v.3.2.6 (Ronquist et al. 2012) with a mixed substitution model (lset $=$ mixed) and gamma-shaped rate variation with a proportion of invariable sites (lset rate $=$ invgamma). Costa Rican IYSV isolates grouped together (supported by 97\% probability) with isolates from Canada, Mexico, New Zealand and the U.S. 
Fig. 2 Bayesian inference phylogenetic tree of Iris yellow spot virus partial nucleocapsid $\mathrm{N}$ ) gene sequences (S genome of tospoviruses) including 15 Costa Rican isolates and selected sequences from around the world. Node labels are posterior probabilities (in percentages). Sequences were aligned with MUSCLE algorithm in MEGA7 and phylogeny inferred with MrBayes v3.2.6 (mixed substitution model and a model (invgamma) combining a proportion of invariable sites and gamma-shaped rate variation models). Scale bar represents number of substitutions per site, and branch breaks correspond to a branch length of 0.6288 substitutions per site

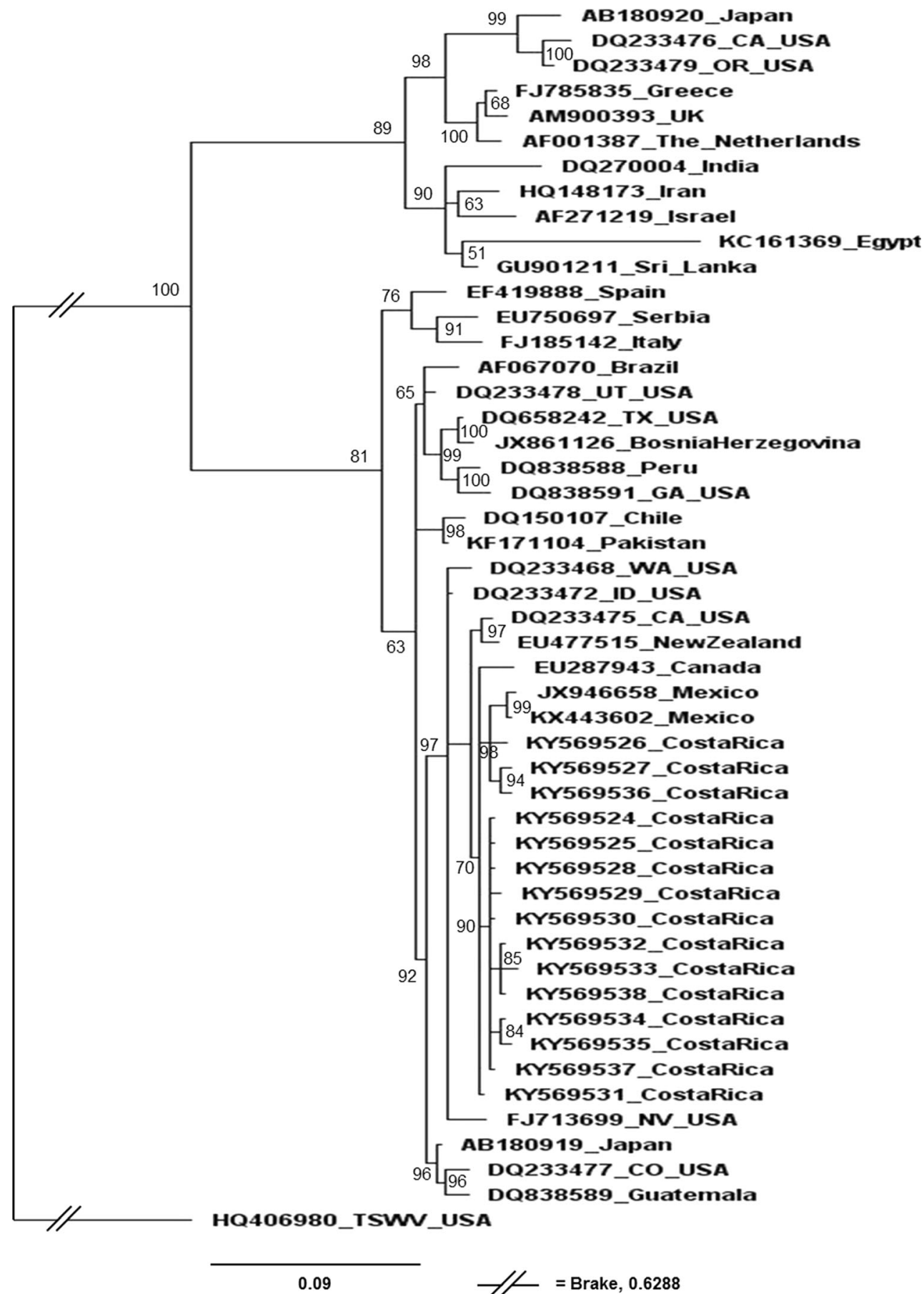

(Fig. 2). The phylogenetic analysis separated IYSV isolates included in this study into two main clades $(100 \%$ support) in accordance to the phylogenetic tree showed by Iftikhar et al. (2014) suggesting that Costa Rican isolates belong to the IYSV Netherlands (IYSV $\mathrm{NL}_{\text {}}$ ) type.

Tospoviruses currently are emerging diseases and economically important plant viruses (Pappu et al. 2009). IYSV is one of those viruses expanding its geographic range. To our knowledge, this is the first report of natural occurrence of IYSV in Costa Rica. How this plant virus arrived to Costa Rica is unknown at this time. The sequences obtained during this work and the notes on its symptomatology and detection will contribute to draw a complete worldwide panorama for virus occurrence, sequence diversity and epidemiology.

Acknowledgements We appreciate the help from extension agents that reported the symptomatology and growers that allowed access to collect samples. This research was funded by Vicerrectoría de Investigación, Universidad de Costa Rica (801-B3-126) and FundaciónUCR (Project 744). 


\section{References}

Edgar RC (2004) MUSCLE: a multiple sequence alignment method with reduced time and space complexity. BMC Bioinform 5:113. doi:10. 1186/1471-2105-5-113

Hanaichi T, Iwamoto T, Malavasi J, Hoshino M, Mizuno N (1986) A stable lead by modification of Sato's method. J Electron Microsc 35:304-306. doi:10.1093/oxfordjournals.jmicro.a050582

Iftikhar R, Ramesh SV, Bag S, Ashfaq M, Pappu HR (2014) Global analysis of population structure, spatial and temporal dynamics of genetic diversity, and evolutionary lineages of Iris yellow spot virus (Tospovirus: Bunyaviridae). Gene 547:111-118. doi:10.1016/j. gene.2014.06.036

Karnovsky MJ (1965) A formaldehyde - glutaraldehyde fixative of high osmolality for use in electron microscopy. J Cell Biol 27:137-138A

Krauthausen HJ, Leinhos GME, Müller J, Radtke PC, Jehle JA (2012) Identification and incidence of Iris yellow spot virus in Allium field crops in Southwest Germany. Eur J Plant Pathol 134:345-356. doi: 10.1007/s10658-012-9993-5

Kritzman A, Lampel M, Raccah B, Gera A (2001) Distribution and transmission of Iris yellow spot virus. Plant Dis 85:838-842. doi:10. 1094/PDIS.2001.85.8.838

Kumar S, Stecher G, Tamura K (2016) MEGA7: molecular evolutionary genetics analysis version 7.0 for bigger datasets. Mol Biol Evol 33: 1870-1874. doi:10.1093/molbev/msw054

Montero-Astúa M, Chacón-Díaz C, Aguilar E, Rodríguez C, Garita L, Villalobos W, Moreira L, Hartung J, Rivera C (2008) Isolation and molecular characterization of Xylella fastidiosa from coffee plants in Costa Rica. J Microbiol 46:482-490. doi:10.1007/s12275-008-0072-8

Nischwitz C, Mullis SW, Csinos AS, Langston DR, Sparks AN, Torrance RL, Rafael Mallaupoma ZC, Inguil Rojas EH, Gitaitis RD (2006) Phylogenetic analysis of the $\mathrm{N}$ gene links Georgia strains of Iris yellow spot virus to strains from Peru. Phytopathology 96:S84. doi:10.1094/PHYTO.2006.96.6.S1

Nischwitz C, Pappu HR, Mullis SW, Sparks AN, Langston DR, Csinos AS, Gitaitis RD (2007) Phylogenetic analysis of Iris yellow spot virus isolates from onion (Allium cepa) in Georgia (USA) and Peru. J Phytopathol 155:531-535. doi:10.1111/j.1439-0434.2007. 01272.x

Pappu HR, Rosales IM, Druffel KL (2008) Serological and molecular assays for rapid and sensitive detection of Iris yellow spot virus infection of bulb and seed onion crops. Plant Dis 92:588-594. doi: 10.1094/PDIS-92-4-0588

Pappu HR, Jones RAC, Jian RK (2009) Global status of tospovirus epidemics in diverse cropping systems: successes achieved and challenges ahead. Virus Res 141:219-236. doi:10.1016/j.virusres.2009. 01.009

Ronquist F, Teslenko M, van der Mark P, Ayres DL, Darling A, Höhna S, Larget B, Liu L, Suchard MA, Huelsenbeck JP (2012) MrBayes 3.2: efficient Bayesian phylogenetic inference and model choice across a large model space. Syst Biol 61:539-542. doi:10.1093/sysbio/ sys029

Schneider CA, Rasband WS, Eliceiri KW (2012) NIH image to ImageJ: 25 years of image analysis. Nat Meth 9:671-675. doi:10.1038/ nmeth. 2089

Smith TN, Wylie SJ, Coutts BA, Jones RA (2006) Localized distribution of Iris yellow spot virus within leeks and its reliable large-scale detection. Plant Dis 90:729-733. doi:10.1094/PD-90-0729

Spurr AR (1969) A low-viscosity epoxy resin embedding medium for electron microscopy. J Ultrastruct Res 26:31-43. doi:10.1016/ S0022-5320(69)90033-1

Srinivasan R, Sundaraj S, Pappu HR, Diffie S, Riley DG, Gitaitis RD (2012) Transmission of Iris yellow spot virus by Frankliniella fusca and Thrips tabaci (Thysanoptera: Thripidae). J Econ Entomol 105: 40-47. doi:10.1603/EC11094

Uga H, Tsuda S (2005) A one-step reverse transcription-polymerase chain reaction system for the simultaneous detection and identification of multiple tospovirus infections. Phytopathology 95:166-171. doi:10. 1094/PHYTO-95-0166

Whitfield AE, Ullman DE, German TL (2005) Tospovirus-thrips interactions. Annu Rev Phytopathol 43:459-489. doi:10.1146/annurev. phyto.43.040204.140017 